\title{
DÜBLIN
}

Technological University Dublin

ARROW@TU Dublin

\section{Design of an underwater cable fault location device to precisely locate submarine cable faults}

\author{
Glenn O'Reilly \\ Technological University Dublin \\ Joseph Kearney \\ Technological University Dublin, joseph.kearney@tudublin.ie \\ John Lawler \\ ESB
}

See next page for additional authors

Follow this and additional works at: https://arrow.tudublin.ie/engscheleart

Part of the Electrical and Computer Engineering Commons

\section{Recommended Citation}

G. O'Reilly, J. Kearney, J. Lawler and T. Looby, "Design of an underwater cable fault location device to precisely locate submarine cable faults," 2017 52nd International Universities Power Engineering Conference (UPEC), 2017, pp. 1-5, doi: 10.1109/UPEC.2017.8231911.

This Conference Paper is brought to you for free and open access by the School of Electrical and Electronic Engineering at ARROW@TU Dublin. It has been accepted for inclusion in Conference papers by an authorized administrator of ARROW@TU Dublin. For more information, please contact arrow.admin@tudublin.ie, aisling.coyne@tudublin.ie,gerard.connolly@tudublin.ie.

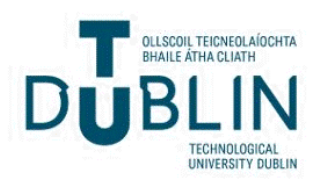


Authors

Glenn O'Reilly, Joseph Kearney, John Lawler, and Tom Looby

This conference paper is available at ARROW@TU Dublin: https://arrow.tudublin.ie/engscheleart/357 


\section{Design of an Underwater Cable Fault Location Device to Precisely Locate Submarine Cable Faults}

\author{
Glenn O'Reilly \\ Dublin Institute of Technology \\ Ireland \\ C13515257@mydit.ie
}

\author{
Dr Joseph Kearney \\ Dublin Institute of Technology \\ Ireland \\ joseph.kearney@dit.ie
}

\author{
Tom Looby \\ ESB Networks \\ Ireland \\ tom.looby@esb.ie
}

\author{
John Lawler \\ ESB Networks \\ Ireland \\ john.lawler@esb.ie
}

\begin{abstract}
The objective of the paper is to develop a robust and reliable method to pinpoint submarine cable faults. Submarine cables have existed for over 100 years but there is still no single method used to determine the precise location of a submarine cable fault. The various methods used to pinpoint cable faults, both submarine and non-submarine were researched and investigated to produce a method which would accurately pinpoint submarine cable faults. From this, the idea of a hydrophone string was derived from a non-submarine pinpointing method currently used. The hydrophone string was tested and it accurately pinpointed the location of the cable fault.
\end{abstract}

Index Terms-- Cable fault, Fault location, Hydrophone, Pinpoint, Pre-location, Submarine cable.

\section{INTRODUCTION}

Submarine cables have existed for over 100 years and throughout the years the role they play has varied. Historically, the main role of submarine cables was to supply power to lighthouses and isolated offshore facilities such as infirmary ships. Nowadays, submarine power cables have been developed for many more uses such as supplying power to islands and to neighbouring countries, the transfer of power from offshore renewable energy resources onto land and the supply of power to offshore facilities such as oil and gas rigs.

As countries strive to meet commitments under various agreements, such as the COP21 and EU2020 agreements, the importance of renewable energy resources increases. In many countries there is a heavy reliance on offshore-based renewable energy production to help meet these targets and because of this submarine power cables are seen as critical infrastructure.

Although submarine cables are designed to withstand the harsh conditions of the marine environment, they have a very high probability of at least one fault occurring during the cable lifetime [1]. Faults are mostly caused by human activities or natural occurrences. Strong tides, landslides, hurricanes and earthquakes are the main effects of nature that cause cable faults, while human activities that cause faults include trawler fishing and ships laying anchors.

Faults in overhead lines are usually transient and selfrestoring, and can be located quite easily and quickly. In comparison, submarine cable faults are much more complex; they are permanent faults and usually take a long time to repair. This puts a high priority on the time and accuracy of locating cable faults.
Locating the fault needs to be quick and accurate in order to restore power to homes and businesses, as well as keeping the cost of the repair as low as possible. Traditionally submarine cables would be hauled onto a barge or ship and the repair would be made there. However, as technology has advanced, there are a number of new methods, including the use of trained divers. Both methods are costly so completing the repair as quickly as possible is a necessity in keeping costs down.

\section{Submarine CABLE FAUlts}

Submarine cables have a high probability of at least one fault occurring during the life of the cable. In order to understand why there is such a high probability of a fault occurring, the different causes of submarine cable damage and the various types of faults will be investigated.

\section{A. Cause of Cable Damage}

The majority of damage to submarine power cables is caused by human activities and natural disasters [4]. Anchors and fishing equipment are the main human causes of damage to submarine cables. Natural disasters that damage submarine cables include strong tides, landslides, hurricanes and earthquakes.

Fishing equipment is the most common cause of damage to submarine cables [2]. Stow nets and pair trawling are two common fishing techniques that cause damage [5]. The stow net technique involves large cone or pyramid shaped nets which are held using large anchors [3]. These large anchors can cause damage to cables when they are dragged along the sea floor as well as the equipment fishermen use to recover lost fishing gear. The other technique that causes damage is pair trawling. This is one of the most popular methods of commercial fishing and involves two trawler boats travelling adjacent to each other with a net between the boats. The net has a heavy rope which weighs the net down and helps to keep the shape. Although this net isn't heavy enough to penetrate the cable, it can become entangled with the submarine cable causing damage [3]. To try to limit the damage fishing equipment causes, fishermen are urged to check charts and use navigation software.

Damage caused by anchors is considered the second most common cause of submarine cable damage [2]. They usually cause damage when they are used outside designated areas or 
are dragged along the sea floor. Although it seems counterintuitive that anchors are dropped in areas where cables are present, it may happen for different reasons. Possibly the most common reason is unsecured anchors on cargo ships becoming loose and dragging along the seabed [5]. As well as this, ships may have to drop anchors in areas of cable if there is an emergency such as a power outage onboard[2].

As mentioned before, the most likely natural occurrences that damage submarine cables are strong tides, landslides, hurricanes and earthquakes. An example of this is the earthquake and landslide that happened in Hengchun, Taiwan in December 2006. The earthquake was a 7.0 magnitude earthquake which triggered the landslide and cut eight submarine cables [7]. Although the natural disasters didn't cause a power outage, many fibre optic cables were ruptured which disrupted not only Taiwan's internet services, but those of many other Asian countries.

Other causes of damage which are worth noting include damage caused during installation and damage caused from joint failures. As well as these causes, there are more obscure causes which have a lower probability of occurring such as ships sinking causing power outages [8] and sharks attempting to bite through fibre optic cables.

\section{B. Fault Types}

Submarine cable faults are classified into different fault types so a suitable method of fault location can be chosen. These different fault types include low and high resistance faults, cable interruptions, intermittent faults and sheath faults [1].

Low resistance faults are defined as faults with a resistance less than $100 \Omega$, while high resistance faults have a resistance in kilo-ohms [1]. A low resistance fault is usually caused by a fault in the insulation which has resulted from water ingress due to external mechanical damage.

A sheath fault usually occurs when the cable jacket has been damaged. These faults are quite common as the cable jacket is on the outer part of the cable, making it more susceptible to mechanical damage.

A cable interruption fault occurs when the cable has been sliced into two or more segments, usually the result of fishing equipment or anchors, as discussed above. An example of this is shown below in Fig. 1, where a cable which connected the islands of Malta and Sicily was dragged by a ship anchor for over $200 \mathrm{~m}$ until the cable was completely severed.

Fig. 1. Cable Interruption Example.

Finally, intermittent faults are faults which only occur above a certain voltage. This voltage is usually less than the operating voltage, resulting in the fault being discovered. This type of fault is caused by defects which occur on either the cable insulation or else in the joints and cable ends [1].

It is essential to determine the type of cable fault which has occurred. By determining the type, the appropriate method of fault location can be chosen.

\section{FAULT PRE-LOCATION}

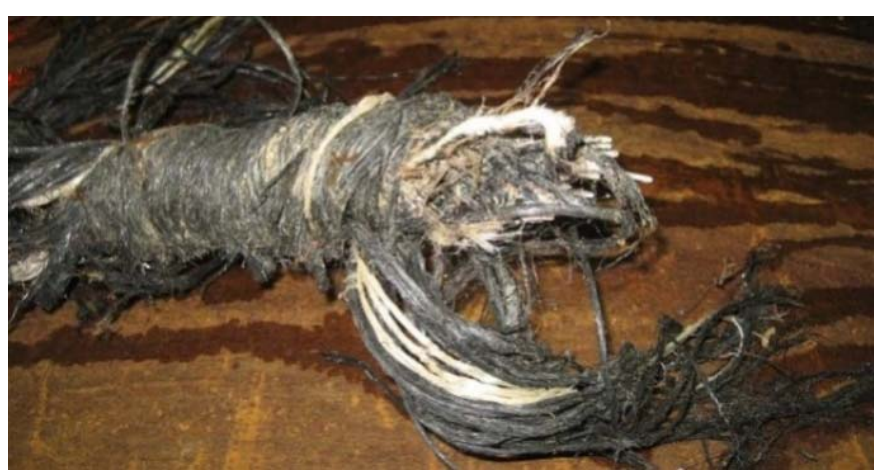

Pre-location involves determining a distance to the fault from a cable end. The distance found using pre-location isn't completely accurate but gives a good indication as to the location of the fault, usually to approximately $1 \%$ of the length of the cable [2]. There are many different methods used for prelocation such as Time Domain Reflectometry (TDR), the Murray Bridge Method as well as the Single and Multiple Impulse Methods. Depending on the fault type the suitable prelocation will be chosen.

TDR is the most widely used method used for pre-locating cable faults. As well as this, TDR devices are the most common and easily accessible pre-location devices available on the market. Although TDR is mostly suited for low resistance faults, it can be adapted to suit other types of faults.

TDR is based on the principle that if a fault occurs on a cable there is an impedance change at the fault location. This method is used for low resistance faults or cable interruptions and has an accuracy of about $1-3 \%$ of the distance to the fault [2].

The TDR device operates by sending an electric impulse down a cable conductor [6]. When the impulse hits the end of the cable or else a cable fault, the pulse (or part of that pulse) travels back to the device. The reflected impulse is used to determine the distance to the fault by using the amount of time the pulse took to reflect back. This relationship can be described by the equation below [2]:

$$
l=t(v / 2)
$$

Where $l=$ the distance to the fault, $t=$ the time taken for the wave to reflect back and $v=$ propagation speed of voltage waves in the cable.

A complete cable break is the easiest type of fault for a TDR to detect [2]. The impulse energy travels down the conductor until it reaches the cable break. A reflection with opposite polarity then travels back through the conductor and can be read from the graph. The magnitude of the reflected wave is much less than the wave sent as most of the energy was lost into seawater. An example waveform for this fault can be seen below in Fig. 2, with a change in impedance that is usually caused by joints.

There is a high reliance on the accuracy of the TDR, as if there are any errors with pre-locating the fault, pin-pointing will be conducted at the wrong section of cable. Errors associated with TDR can include miss-calibration of the TDR 
device or errors in the calculation of the propagation speed of voltage waves in the cable (v) [1].

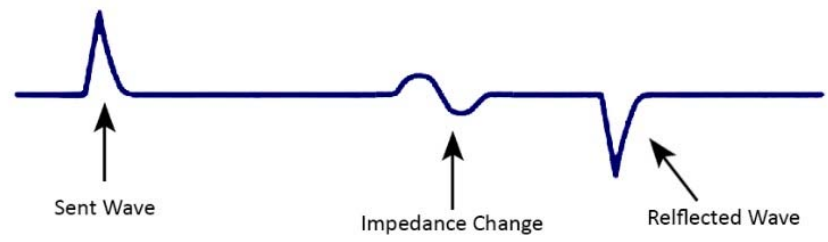

Fig. 2. TDR Waveform Example

\section{FAULT PINPOINTING}

As discussed there are many different methods to pre-locate faults. However, all of the available methods are capable of only locating faults with a percentage error. Although only a small percentage, the error can still result in a fault location that ranges over a couple of kilometres, making it impracticable for divers or remotely operated underwater vehicles (ROV) to locate or fix the fault. By using the known pre-location, pinpointing methods can be used to determine the exact fault location.

A hydrophone is a device used to listen to underwater sounds. It operates on the principle of turning acoustic energy into electrical energy, like a microphone, but detects sounds in water rather than air. The first hydrophone was created by scientists in the 1800's when they developed an echo-sounding military device used to locate submarines and icebergs. Hydrophones are usually made of piezoelectric material. The material produces electrical charges when it experiences a pressure change, meaning the pressure changes produced by a sound wave can be detected.

A hydrophone array is several hydrophones used together in a certain formation. The arrays can be set up in lines or different shapes and can then be used in several ways, such as laid on the seafloor or towed vertically or horizontally by a boat. This is useful as sounds detected at different times by each hydrophone allows for the source of the sound to be pinpointed. A hydrophone array is a better option than a single hydrophone when looking to pinpoint a specific sound. The array makes it possible to filter extra noise that may be present, in other words a hydrophone array provides a better signal-tonoise ratio. The array also allows the sound source to be detected even if it is quiet.

For pinpointing faults, hydrophone arrays can be used to determine the exact fault location by 'thumping' the cable and determining which hydrophone experienced the largest sound. Cable 'thumping' involves supplying a high voltage to the cable, which results in a high-current arc at the fault location which creates a loud noise [9]. This method does have several advantages and disadvantages, but the main disadvantage is the degradation of the cable insulation caused by the high current.

Although this method is a relatively new idea, an example of how the hydrophone array could be used is shown in Figure 8. The image isn't to scale but shows the concept of an array of hydrophones towed from the back of a boat. When cable thumping occurs, a noise will be created (shown as cable fault in the image) and subsequently it will be detected by the first, second and third hydrophone.

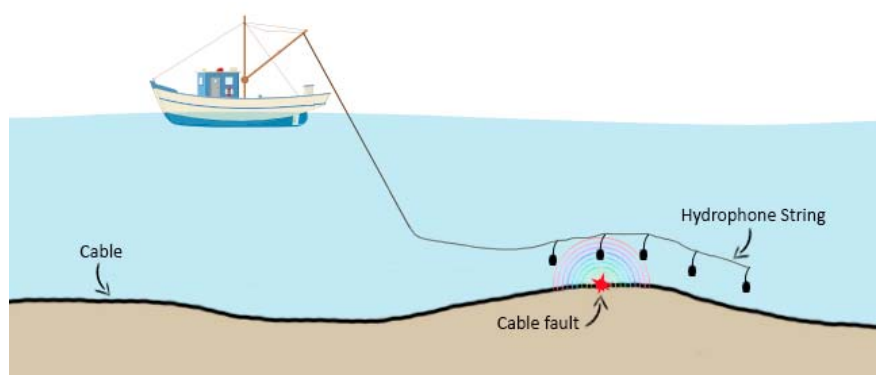

Fig. 3. Hydrophone Array Example

\section{TESTING}

The hydrophone test string was manufactured and supplied by Geotomographie, who specialise in seismic borehole equipment. Initially, the BHC4 hydrophone string was chosen but unfortunately it was out of stock at the time. As a result of this Geotomographie sent the BHC2 hydrophone test string. The BHC2 string is very similar to the BHC4 string, with the main difference being the $\mathrm{BHC} 2$ is a passive hydrophone string, meaning no external power is required. The hydrophone test string consisted of 24 hydrophones spaced 1 metre apart that are connected to a DAQLink III seismograph, which was also supplied by Geotomographie.

The DAQLink III is a 24 bit analog to digital acquisition system that is used to communicate with VScope software through the use of an Ethernet cable. The VScope software allows for seismographic results to viewed, stored and analysed.

\section{A. Procedure}

The testing of a cable fault was conducted in a pond located in ESB Networks Leopardstown on the 1st of May 2017. The test cable used was a $20 \mathrm{kV}$ XPLE insulated cable and a deliberate fault was put on the cable at a location approximately 15 metres from the beginning of the cable. This was done by removing a some of the cable jacket and cutting a small section out of the XPLE insolation, shown later in Figure 19.

The $20 \mathrm{kV}$ cable was laid along the floor of the pond with cable terminals remaining above the water so the cable could be thumped using an ESB Networks test van which had a fitted generator. Once the cable was positioned correctly the hydrophone string was laid alongside the cable, the DAQLink III and VScope Software were connected and testing could begin. The setup can be seen below in Fig. 4 .

Different voltage levels supplied from the test van were tested until a level of $5 \mathrm{kV}$ was determined as suitable as it could be read and analysed on the VScope software. The sampling interval of $0.21 \mathrm{mSec}$ ( $48 \mathrm{kHz}$ sampling frequency) was selected as not only was it suggested by the manufacturer, but a sampling frequency of $48 \mathrm{kHz}$ is greater than the $44 \mathrm{kHz}$ used to sample speech and therefore deemed suitable. 


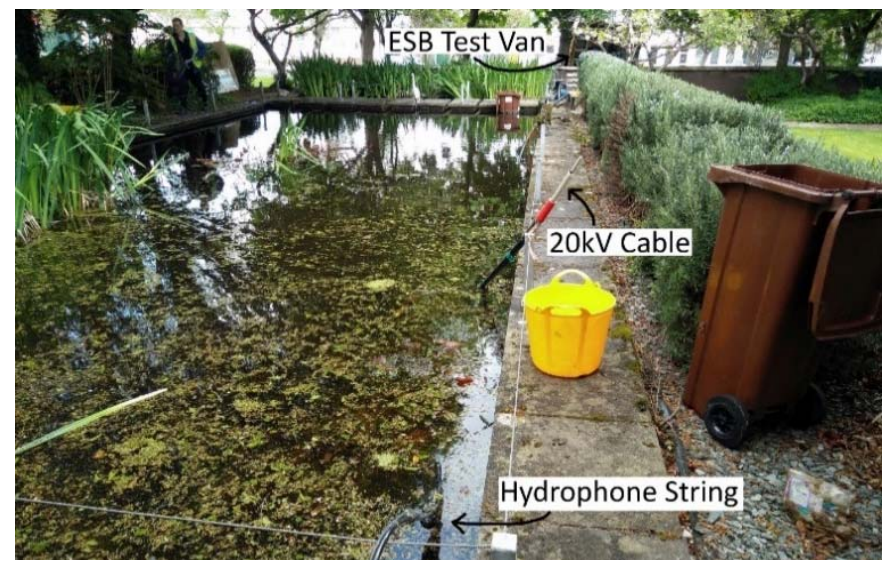

Two tests were performed which had a duration of approximately 30 seconds. During this duration, the cable was thumped 5 times at intervals of approximately 6 seconds. Fig. 4. Testing Setup

\section{B. Results}

The resulting noise analysis graph for the for the test conducted can be seen below in Fig. 5. The graph shows the noise experienced by each hydrophone over the 30 seconds and plots the hydrophone number on the x-axis, and the noise converted into a voltage on the y-axis.

From the graph, the fault can be seen to occur at hydrophone 11 as it has the biggest amplitude. After the testing was finished, the $20 \mathrm{kV}$ cable and the hydrophones were lifted out of the water together. This verified that fault location was just to the left of the eleventh hydrophone as shown in Fig. 7. Not only does it verify the result but it also shows the high accuracy of this method.

The noise sidebands can also be seen in Fig. 5 which show the sound waves travelling away from the origin of the noise, with less amplitude the further they travel. The analysis of the sidebands allows for a higher accuracy of fault location. As hydrophone 10 has a higher amplitude than hydrophone 12 this indicates the fault occurs just to the left of hydrophone 11.

Another result obtained from the first test is the seismic plots as shown in Fig. 6. This plot shows the seismic activity and plots each hydrophone on the x-axis and on the time y-axis. As seen below, approximately 4 seconds elapse before cable

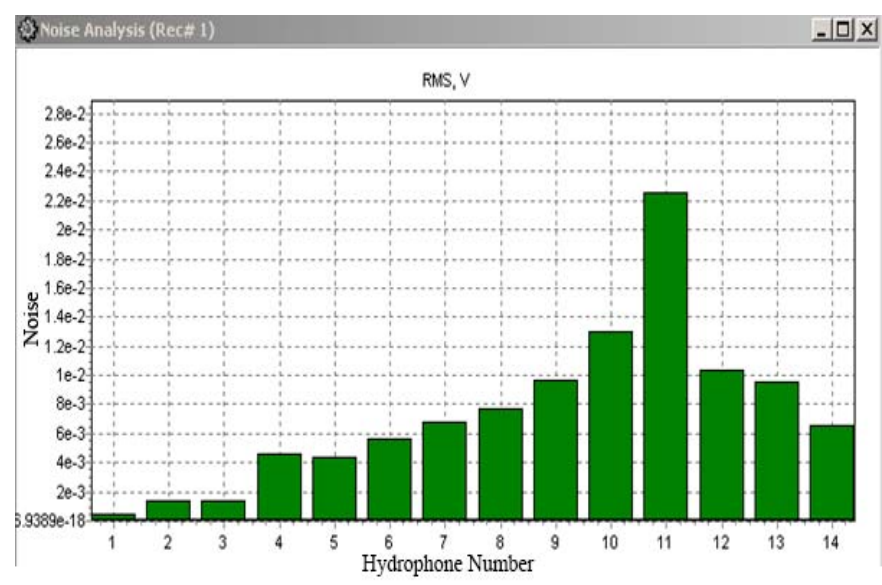

thumping begins. Then after this the cable is thumped 4 more times with a break of about 6 seconds between each thump. Fig. 5. Noise Analysis

Fig. 6. Seismic Plots

Initially it was hoped that the seismic plots would be able to identify the fault location but because the amplitude of the sound waves was so big it could only be determined from the noise analysis graph. However, these graphs are still useful as they can be used to confirm the cable has been thumped and how regularly.

When testing the noise created from the cable thump was easily heard above water, but if the cable was at a lower depth this wouldn't be possible. As well as this a noise analysis graph could still be produced even if the cable fails to thump. This graph could be produced from other sounds in the submarine environment and therefore provide an incorrect fault location.

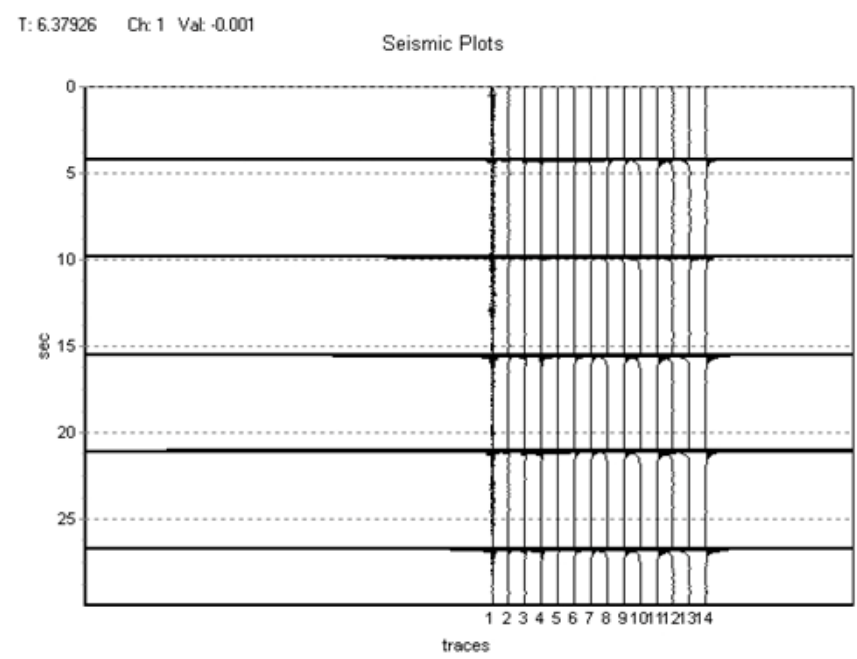

Therefore, the seismic graph must be used to confirm the cable thump was successful.

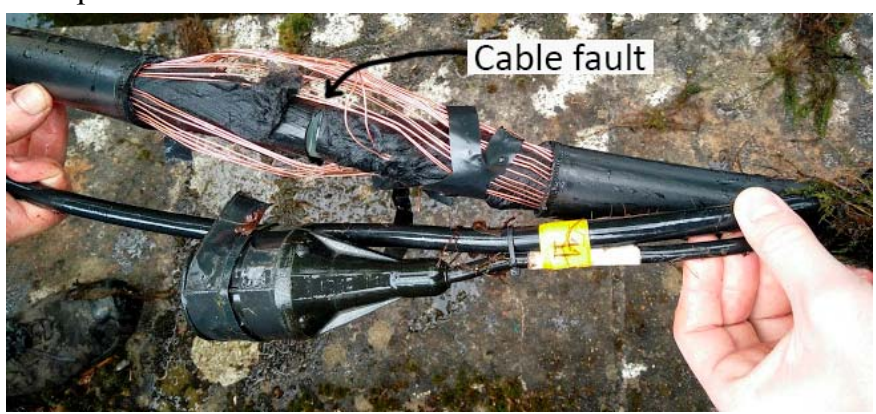

Fig. 7. Fault \& Hydrophone

\section{Testing Conclusion}

Overall the testing proved the high accuracy and reliability of the hydrophone method. The fault was precisely located at the eleventh hydrophone. If the fault was to occur exactly between two hydrophones, the amplitude of each hydrophone on the noise analysis graph would be equal and the fault would be determined to be in the middle of the two hydrophones.

The equipment was very robust and durable as well as being relatively straightforward to use once familiar with. A second set of results was also recorded which can be seen in Appendix 
A. These results are most identical to the first set which show the hydrophone is a reliable method.

As mentioned before the hydrophone string used was a BHC2 type string which are passive. The sensitivity of this method could be improved by using a non-passive (require external power) but as shown, a passive hydrophone string has the ability to precisely locate a submarine cable fault.

\section{CONCLUSION}

The main objective of this project was to design an underwater cable fault location device to precisely locate submarine cable faults. This objective was completed successfully as the hydrophone device is capable of locating the exact location of submarine cable fault. By studying how submarine cable faults occur and the different causes of faults, a better understanding and appreciation of the current methods used to the locate faults was obtained.

From the research of these different methods it was discovered that submarine cable fault location was broken down into two different categories, pre-location and pinpointing. Pre-location is used to give a good indication to the fault location but doesn't have complete accuracy. Pre-location is a well-researched area and the most popular method used is Time Domain Reflectometry (TDR). There are many widely available resources on the market to implement TDR which were developed from the over-ground technology use of TDR.

Like pre-location, there is many methods available to pinpoint cable faults. However, there isn't a most popular method which is commonly used which resulted in this being the main task of the project. The idea of the hydrophone string stemmed from an over-ground method used in ESB Networks to detect faults in buried cables. This device involves a single microphone type element which is operated by a technician to pinpoint the fault. This idea was adapted to submarine conditions by using a hydrophone so sound could be detected underwater and using a string of hydrophones to avoid the use of a technician.

The hydrophone string was sourced from a German company called Geotomographie and tested with a $20 \mathrm{kV}$ cable in a pond in ESB Networks, Leopardstown. The device proved successful as it could pinpoint the exact location of the fault. Although the testing gave extremely accurate results further testing may be required on different types of cables at deeper depths.
As well as this further testing, further work on the hydrophone string such as the introduction magnets could be investigated before the hydrophone string can be classified as the most reliable and robust method of pinpointing submarine cable faults.

\section{ACKNOWLEDGEMENTS}

I would firstly like to express my sincere thanks and appreciation to my project supervisor in Dublin Institute of Technology, Dr Joseph Kearney, for all the help and guidance that he has given me throughout the duration of the project.

I would also like to thank Tom Looby and John Lawler from ESB Networks for all the support and expertise they provided. I am very thankful for getting the opportunity of working on a real-life problem.

\section{REFERENCES}

\section{Periodicals:}

[1] M. M. G. M. Manfred Bawart, "Diagnosis and Location of Faults in Submarine Power Cable," IEEE Electrical Insulation Magazine,, 2016

Books:

[2] T. Worzyk, Submarine Power Cables - Design, Installation, Repair, Environmental Aspects, Springer, 2009.

Technical Reports:

[3] Stephen Drew \& Alan Hopper, Fishing And Submarine Cables, Working Together, Second Edition, 2009.

Papers from Conference Proceedings (Published):

[4] APEC, "Submarine Cable Network Security", Singapore, 2009.

[5] Stephen Drew, "Causes of Cable Faults and Repairs in Regional", Tyco Telecommunications, ICPC Executive Committee.

Websites:

[6] "History High Voltage Cables Timeline | Preceden", Preceden.com, 2017. [Online]. Available: https://www.preceden.com/timelines/39278history-high-voltage-cables. [Accessed: 05- March- 2017].

[7] "Cables cut after Taiwan Earthquake 2006", Submarine Networks, 2017. [Online]. Available: http://submarinenetworks.com/news/cables-cutafter-taiwan-earthquake-2006. [Accessed: 10- April- 2017].

[8] "Roy A. Jodrey", Tekdiv.com, 2010. [Online]. Available: http://www.tekdiv.com/index.php?option=com_content\&view=article\& id=45\&Itemid=54\&lang=en. [Accessed: 11- April- 2017].

[9] D. Koep, "Locating That Underground Cable Fault", Electrical Construction \& Maintenance (EC\&M) Magazine, 1999. [Online]. Available: http://beta.ecmweb.com/content/locating-underground-cablefault?utm_test=redirect\&utm_referrer=. [Accessed: 11- March- 2017]. 